\title{
STABILITY-INDICATING METHODS FOR THE DETERMINATION OF SERTACONAZOLE NITRATE BY MICELLE-ENHANCED SPECTROFLUORIMETRY AND TLC-DENSITOMETRY
}

\author{
Nahla Nour El-Din Ahmed Salama* and Afaf Osman Mohamed \\ National Organization for Drug Control and Research (NODCAR), 6-Abu Hazem Street, \\ Pyramids Ave., P.O. Box 29, 35521, Giza, Egypt
}

(Received May 17, 2008; revised January 17, 2009)

\begin{abstract}
Two sensitive and selective stability-indicating methods were developed for the determination of sertaconazole nitrate $\left(\mathrm{Ser}-\mathrm{NO}_{3}\right)$, in the presence of its acid, alkaline and oxidative degradation products. The first method was based on measuring the fluorescence intensity of the drug at $\lambda_{\mathrm{ex}} / \lambda_{\mathrm{em}}=231 \mathrm{~nm} / 312 \mathrm{~nm}$. The influence of micelle medium on the fluorescence emission was studied. The nonionic surfactant of Triton ${ }^{\circledR} \mathrm{X}-100$ showed strong sensitizing effect for the fluorescence. The fluorescence intensity plot was linear over concentrations $0.5-5$ $\mu \mathrm{g} \mathrm{mL}{ }^{-1}$ with mean percentage recoveries $100.59 \pm 1.49 \%$. The second method was based on TLC separation of the drug from its degradation products followed by densitometric measurement of the intact drug spot at $302 \mathrm{~nm}$. The developing system used for separation was chloroform-acetone-33 \% ammonia $(14: 2: 0.1 \mathrm{v} / \mathrm{v} / \mathrm{v})$. The linear range was $1-8 \mu \mathrm{g} / \mathrm{spot}$ with mean percentage recoveries $100.07 \pm 1.97 \%$. The methods were validated according to ICH guidelines. Statistical analysis of the results revealed high accuracy and good precision. The suggested procedures could be used for the determination of sertaconazole nitrate in drug substance and drug products as well as in presence of its degradation products.
\end{abstract}

KEY WORDS: Stability-indicating, Micelle-enhanced fluorescence, TLC-densitometry, Sertaconazole nitrate, Drug products

\section{INTRODUCTION}

Sertaconazole nitrate (Ser-NO $)_{3}, \quad$ (RS)-1-[2-[(7-chlorobenzothiophen-3-yl)methoxy]-2-(2,4dichlorophenyl)-ethyl]imidazole nitrate Figure 1 , is a broad spectrum antifungal agent with excellent activity against yeasts, dermatophytes and opportunistic fungi. It has a good safety profile, sustained cutaneous retention, and low systemic absorption, all of which make it ideal for topical applications [1-4]. The official method for the determination of Ser- $\mathrm{NO}_{3}$ is nonaqueous titration with perchloric acid, determining the end point potentiometrically [5]. The literature survey revealed that few attempts have been made for the analysis of Ser- $\mathrm{NO}_{3}$ in pharmaceutical dosage forms, liquid chromatography (LC) and capillary electrophoresis (CE), $[6,7]$.

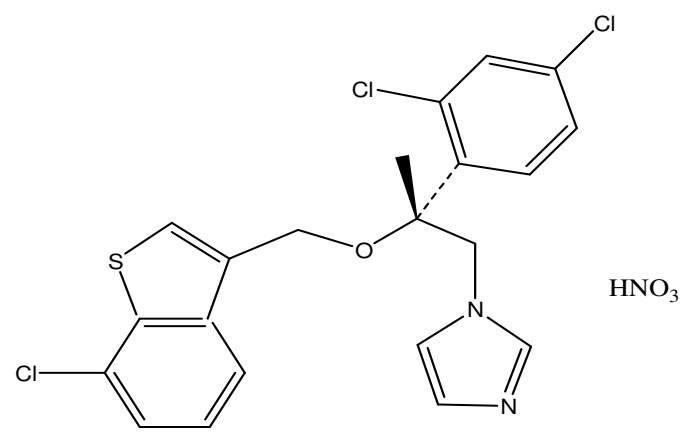

Figure 1. Chemical structure of sertaconazole nitrate.

*Corresponding author. E-mail: Salama_Nahla2004@hotmail.com 
Among the various methods available for the determination of drugs, spectrofluorimetry and TLC continue to be very popular, because of their simplicity, specificity and low cost [8-11]. This study presents new spectrofluorimetric and TLC-densitometric methods for the assay of Ser- $\mathrm{NO}_{3}$.

The applicability of the developed methods was evaluated through the determination of Ser$\mathrm{NO}_{3}$ in drug substance, in laboratory prepared mixtures containing different percentages of degradation products as well as in drug products.

Instrumentation

\section{EXPERIMENTAL}

Fluorescence spectra and measurements were taken on a Shimadzu spectrofluorimeter Model RF-1501 equipped with xenon lamp and 1-cm glass cells. Excitation and emission wavelengths were set at $\lambda_{\text {ex }} / \lambda_{\text {em }}=231 \mathrm{~nm} / 312 \mathrm{~nm}$.

TLC plates $\left(20 \times 20 \mathrm{~cm}\right.$, aluminium plates precoated with $0.25 \mathrm{~mm}$ silica gel $\left.\mathrm{F}_{254}\right)$ were purchased from E. Merk Co. and the samples were applied to the TLC plates using $25 \mu \mathrm{L}$ Hamilton microsyringe. A Shimadzu dual wavelength flying spot densitometer Model CS-9301 PC was used. The experimental conditions of the measurements were: wavelength $=302 \mathrm{~nm}$, photo mode $=$ reflection, scan mode $=$ zigzag, swing width $=5$.

\section{Materials and reagents}

Sertaconazole nitrate (Ser-NO3) was kindly obtained from October Pharm. Co. (Egypt). Its purity was labelled to be $99.74 \pm 1.46 \%$ according to the official method [5]. Dermofix cream and powder were obtained from October Pharm. Co. (Egypt) and were labelled to contain 20 $\mathrm{mg} / \mathrm{g}$. All chemicals used were of analytical grade. Sodium dodecyl sulfate (BHD, Egypt), cetylpyridinium bromide (Prolabo, Egypt), Tween 40, Tween 80 (Aldrich, Egypt), Triton TX-100 (aMRGSCO, Co., Egypt), methanol, chloroform, acetone (Lab-Scan, Egypt), hydrochloric acid (Scientific Fischer Co., Egypt), sodium hydroxide, ammonia $33 \%$ (Adwic Co., Egypt), hydrogen peroxide $30 \%$ (Honil-Limited, Egypt) were used as received.

Standard solutions. For spectrofluorimetry and TLC methods $1 \mathrm{mg} \mathrm{mL}^{-1}$ were prepared by dissolving appropriate amounts of the drug in methanol. These stock solutions were subsequently used for preparation of working standards in concentration ranges of 5-50 $\mu \mathrm{g} \mathrm{mL}^{-1}$ and $100-800 \mu \mathrm{g} \mathrm{mL}^{-1}$ by further dilution with water and methanol for spectrofluorimetry and TLC methods, respectively. All stock solutions were kept in refrigerator at $4{ }^{\circ} \mathrm{C}$, which were stable for at least 2 weeks.

Preparation of degradation products $1.0 \mathrm{mg} \mathrm{mL}^{-1}$. The degradation products were prepared by heating $10 \mathrm{mg}$ of Ser- $\mathrm{NO}_{3}$ with $20 \mathrm{~mL}$ of $0.5 \mathrm{M} \mathrm{NaOH}$ for alkaline degradation and with $20 \mathrm{~mL}$ of $1 \mathrm{M} \mathrm{HCl}$ for acid degradation at $100{ }^{\circ} \mathrm{C}$ on hot plate for one and half hours. For oxidative degradation, $10 \mathrm{mg}$ of Ser- $\mathrm{NO}_{3}$ was left with $5 \mathrm{~mL}$ of $30 \% \mathrm{H}_{2} \mathrm{O}_{2}$ over night. Each of the acid and alkaline degradation solution was neutralized and evaporated on water bath. Then, the solutions were completed to $10 \mathrm{~mL}$ with methanol. For oxidative degradation, the solution was evaporated on water bath and completed to $10 \mathrm{~mL}$ with methanol.

\section{Method development}

Spectrofluorimetric method. Aliquots of working aqueous solution equivalent to $5.0-50 \mu \mathrm{g} / \mathrm{mL}$ Ser. $\mathrm{NO}_{3}$ were transferred into a series of $10 \mathrm{~mL}$ volumetric flask followed by $1 \mathrm{~mL}$ of $1 \mathrm{M}$ 
$\mathrm{NaOH}$ and $1 \mathrm{~mL}$ of $0.04 \%$ Triton $^{\circledR} \mathrm{X}-100$. The volume was completed to the mark with water. The solution was mixed at room temperature for $5 \mathrm{~min}$. The fluorescence intensity was measured at $\lambda_{\mathrm{ex}} / \lambda_{\mathrm{em}}=231 \mathrm{~nm} / 312 \mathrm{~nm}$. To obtain the standard calibration graph the concentrations were plotted versus fluorescence intensity, and the linear regression equation was computed.

TLC-method. The plates were developed in chloroform - methanol - $33 \%$ ammonia (14:2:0.1 $\mathrm{v} / \mathrm{v} / \mathrm{v})$ as developing system. For detection and quantification, $10 \mu \mathrm{L}$ of each of sample solution and the standard solutions of different concentrations within the quantification range were applied as separate compact spots $20 \mathrm{~mm}$ apart and $20 \mathrm{~mm}$ from the bottom of the TLC plate using $25 \mu \mathrm{L}$ Hamilton microsyringe. The chromatographic tank was saturated with mobile phase for $30 \mathrm{~min}$. The plates were developed up to $16 \mathrm{~cm}$ in the usual ascending way, air dried and scanned for the studied drug at $302 \mathrm{~nm}$, using the mentioned instrumental parameters.

Assay of laboratory prepared mixtures

To assess the stability indicating nature of the proposed methods, synthetic mixtures containing different ratios of $\mathrm{Ser}-\mathrm{NO}_{3}$ and its degradation product (acid, alkaline and oxidative) were prepared and analyzed by the suggested procedures.

Assay of drug products

$2.5 \mathrm{~g}$ of pharmaceutical cream and powder were weighed into a $25 \mathrm{~mL}$ beaker and dispersed with methanol using a stirring rod for $10 \mathrm{~min}$. Each solution was transferred quantitatively to a $50 \mathrm{~mL}$ measuring flask to obtain concentration of $1 \mathrm{mg} \mathrm{mL}^{-1}$. Each flask was sonicated for 15 min and diluted to the mark with methanol. The solution was filtered for the powdered form, while an aliquot was centrifuged for $15 \mathrm{~min}$, for cream. Appropriate solutions were prepared to obtain $10 \mu \mathrm{g} \mathrm{mL}^{-1}$ in water and methanol for fluorimetric and $400 \mu \mathrm{g} \mathrm{mL}^{-1}$ in methanol for TLCdensitometric methods. Then the procedures were completed as described for the construction of calibration graphs for both methods.

\section{Spectrofluorimetric method}

\section{RESULTS AND DISCUSSION}

Spectral characteristics. The present work depends on measuring native fluorescence intensity of $\mathrm{Ser}-\mathrm{NO}_{3}$ in alkaline aqueous micelle-media. The method proved to be stability indicating method as the degradation products do not exhibited native fluorescence (Figure 2).

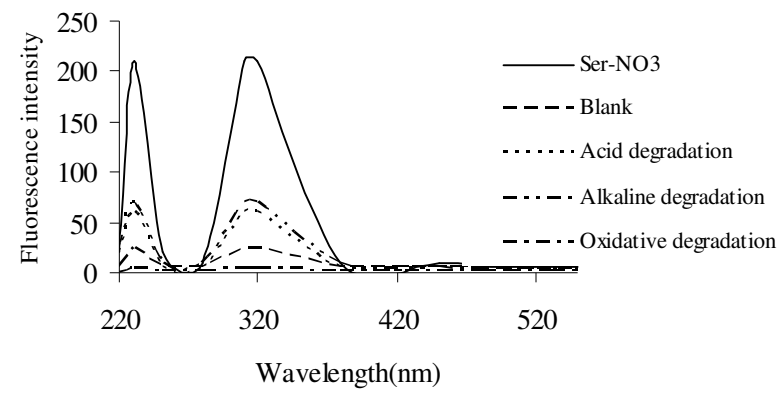

Figure 2. Excitation and emission spectra of $4 \mu \mathrm{g} \mathrm{mL} L^{-1}$ of sertaconazole nitrate and its degradation products at $\lambda_{\mathrm{ex}} / \lambda_{\mathrm{em}}=231 \mathrm{~nm} / 312 \mathrm{~nm}$.

Bull. Chem. Soc. Ethiop. 2009, 23(2) 
Ser- $\mathrm{NO}_{3}$ showed native fluorescence signal in alkaline aqueous solution. The effects of different solvents on the fluorescence intensity have been studied. The higher fluorescence is in order aqueous alkali $>$ water $>$ cyclohexane $>$ methanol $>$ acetonitrile $>$ aqueous acid as presented in Table 1.

Table 1. Effect of solvent on the fluorescence intensity of sertaconazole nitrate $3 \mu \mathrm{g} \mathrm{mL}$.

\begin{tabular}{|l|c|}
\hline Solvents & $\begin{array}{c}\text { Fluorescence intensity } \\
\lambda_{\mathrm{Ex}} / \lambda_{\mathrm{Em}}=231 \mathrm{~nm} / 312 \mathrm{~nm}\end{array}$ \\
\hline Acetonitrile & 37 \\
Cyclohexane & 82 \\
Methanol & 80 \\
Water & 100 \\
$1.0 \mathrm{M} \mathrm{NaOH}$ & 188 \\
$0.1 \mathrm{M} \mathrm{NaOH}$ & 150 \\
$0.1 \mathrm{M} \mathrm{H}_{2} \mathrm{SO}_{4}$ & 29 \\
$0.1 \mathrm{M} \mathrm{HCl}^{\mathrm{M} \mathrm{M} \mathrm{H}_{3} \mathrm{COOH}}$ & 47 \\
$0.1 \mathrm{M} \mathrm{CH}$ & 34 \\
\hline
\end{tabular}

The fluorimetric properties of Ser- $\mathrm{NO}_{3}$ were studied in different micellar media by preparing $4 \mu \mathrm{g} \mathrm{mL}{ }^{-1}$ solutions each with $1 \mathrm{~mL}$ of $0.04 \%$ of surfactants in aqueous alkaline media. An increase in fluorescence intensity was observed only when Triton ${ }^{\circledR} \mathrm{X}-100$ (non-ionic) was added. As can be seen in Figure 3, the enhancement ability sequence Triton ${ }^{\circledR}$ X-100 > Tween40 $>$ Tween $80>$ SDS $>$ CPB.

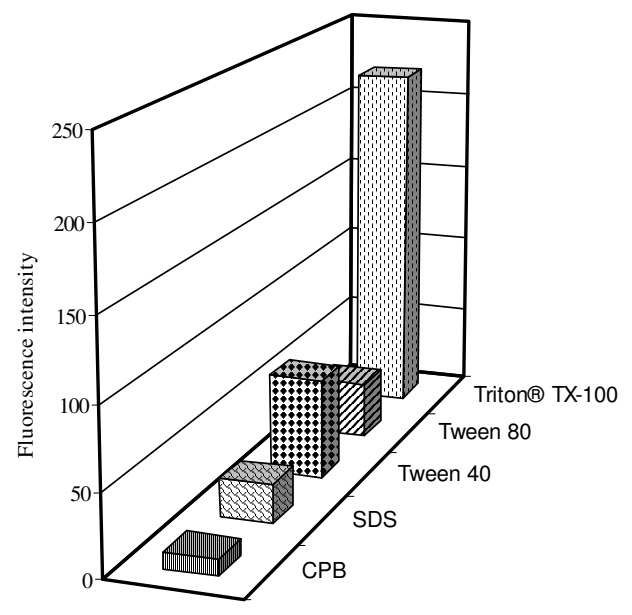

Figure 3. Effect of different surfactants on fluorescence intensity of sertaconazole nitrate $4 \mu \mathrm{g}$ $\mathrm{mL}^{-1}$ at $\lambda_{\mathrm{ex}} / \lambda_{\mathrm{em}}=231 \mathrm{~nm} / 312 \mathrm{~nm}$.

TLC- method

Chromatographic conditions. The experimental conditions for the TLC method such as mobile phase composition, scan mode, and wavelength of detection were optimized to provide accurate, precise, and reproducible results for the determination $\mathrm{Ser}-\mathrm{NO}_{3}$ in the presence of its acid,

Bull. Chem. Soc. Ethiop. 2009, 23(2) 
alkaline, and oxidative degradation products. The scan mode chosen was the zigzag mode and the wavelength of scanning chosen was $302 \mathrm{~nm}$. The method is based on the difference in the $R_{f}$ value of $\mathrm{Ser}-\mathrm{NO}_{3}$ and its degradation product. The $\mathrm{R}_{\mathrm{f}}$ value of $\mathrm{Ser}-\mathrm{NO}_{3}$ is 0.62 while its degradation product zero as shown in Figure 4. By applying this technique, a linear correlation was obtained between the area under the peak and the concentration in the range of 1.0-8.0 $\mu \mathrm{g} / \mathrm{spot}$ as shown in Figure 5, from which the linear regression equation was calculated.

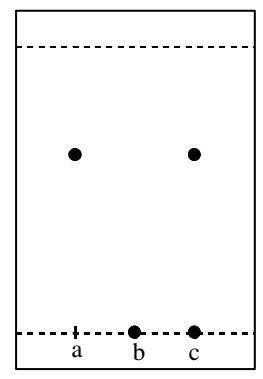

Figure 4. Thin layer chromatogram showing resolution of a) sertaconazole nitrate, b) degradation product, and c) synthetic mixture.

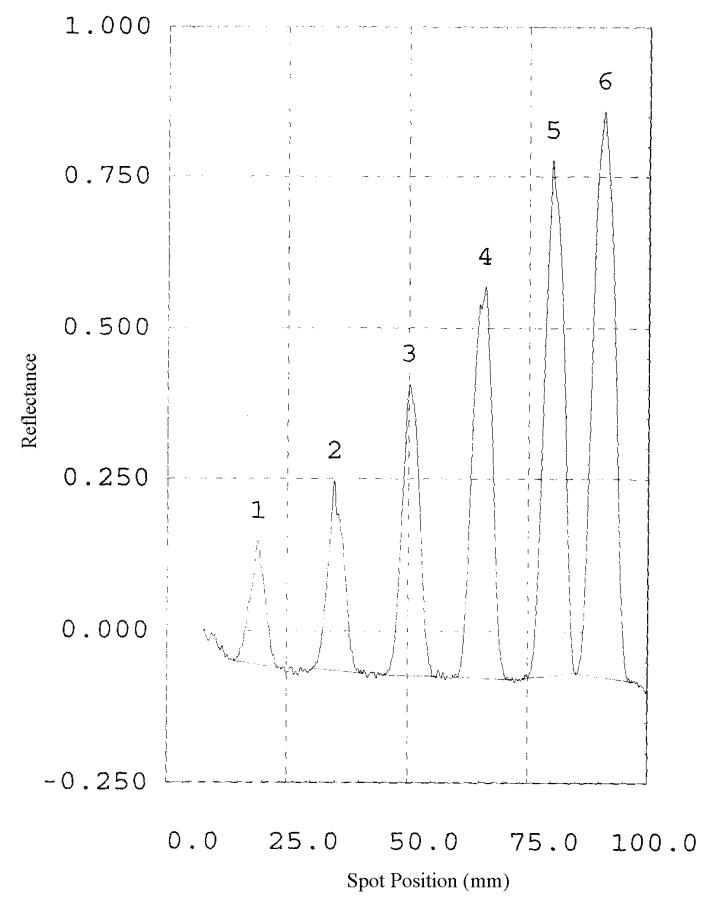

Figure 5. Densitometric scanning profile for TLC-chromatogram of different concentrations of sertaconazole nitrate $(1-8 \mu \mathrm{g} / \mathrm{spot})$ at $302 \mathrm{~nm}$.

Bull. Chem. Soc. Ethiop. 2009, 23(2) 
Analytical parameters

Table 2 contains the figures of merit of the proposed methods. The data were fitted by leastsquare regression and the calibration equations are shown. The concentration ranges studied, were $0.5-5.0 \mu \mathrm{g} \mathrm{mL}^{-1}$ and $1-8 \mu \mathrm{g} /$ spot for fluorimetric and TLC methods, respectively.

Table 2. Results of assay validation obtained by applying the proposed spectrofluorimetric and TLCdensitometric methods for the determination of sertaconazole nitrate in drug substance.

\begin{tabular}{|l|c|c|}
\hline \multirow{2}{*}{ Parameters } & \multicolumn{2}{|c|}{ Sertaconazole nitrate } \\
\cline { 2 - 3 } & Spectrofluorimetric & TLC-densitometric \\
\hline Linearity range & $0.5-5 \mu \mathrm{g} \mathrm{mL}^{-1}$ & $1.0-8.0 \mu \mathrm{g} / \mathrm{spot}$ \\
Accuracy & $100.59 \pm 1.48$ & $100.40 \pm 1.54$ \\
Mean \pm RSD \% & & \\
Precision & & \\
Intraday (n=9) & $99.52 \pm 1.20$ & $100.85 \pm 1.63$ \\
Mean \pm RSD\% & & \\
Interday (n=9) & $98.87 \pm 1.40$ & $99.55 \pm 1.82$ \\
Mean \pm RSD\% & & \\
Specificity & $99.18 \pm 1.05$ & $101.69 \pm 1.38$ \\
Mean \pm RSD\% & & \\
Regression & 27.479 & 452.56 \\
Slope & 102.18 & 7.23 \\
SE of slope & 1.59 & 395.24 \\
Intercept & 0.9996 & 35.50 \\
SE of intercept & 2.044 & 0.9996 \\
Correlation coefficient & $0.15 \mu \mathrm{gL}^{-1}$ & 41.39 \\
SE of estimation & $0.50 \mu \mathrm{g} \mathrm{mL}$ & $0.30 \mu \mathrm{g} / \mathrm{spot}$ \\
LOD & & $1.00 \mu \mathrm{g} / \mathrm{spot}$ \\
LOQ &
\end{tabular}

Table 2 shows good reproducibility for the proposed procedures when applied to pure sample of Ser- $\mathrm{NO}_{3}$ over three concentration level $\left(1,2,4 \mu \mathrm{g} \mathrm{mL}{ }^{-1}\right)$ and $(2,4,6 \mu \mathrm{g} / \mathrm{spot})(\mathrm{n}=9)$ for both methods. The relative standard deviations are less than $2.0 \%$ indicate good precision.

The detection limit (LOD) was defined as the concentration of drug giving a signal to noise ratio of 3:1 and LOQ was estimated using the $10 \sigma$ criterion $[12,13]$. The obtained results are stated in Table 2.

Table 3 shows comparison between the proposed methods and official method [5] for the determination of Ser- $\mathrm{NO}_{3}$ from which the calculated $t$ and $F$ are less than the corresponding theoretical values indicating that there is no significant difference between the two methods with respect to both precision and accuracy.

Table 3. Statistical comparison between the results obtained by the proposed methods and the official method.

\begin{tabular}{|l|c|c|l|}
\hline Values & Spectrofluorimetric method & TLC-densitometric method & Official $^{\mathrm{a}}$ method \\
\hline Mean & 100.59 & 100.07 & 99.74 \\
SD & 1.49 & 1.97 & 1.46 \\
Variance & 2.22 & 3.88 & 2.13 \\
SE & 0.60 & 0.80 & 0.65 \\
$\mathrm{n}$ & 6 & 6 & 5 \\
$t(1.833)^{\mathrm{b}}$ & 0.96 & 0.32 & \\
$F(6.30)^{\mathrm{b}}$ & 1.03 & 2.33 & \\
\hline
\end{tabular}

${ }^{\mathrm{a}}$ Potentiometric method described in ref. 5. ${ }^{\mathrm{b}}$ Theoretical values, at $\mathrm{P}=0.05$.

Bull. Chem. Soc. Ethiop. 2009, 23(2) 
Assay of laboratory prepared mixtures

Table 4 shows the results of determination seven synthetic mixtures of the intact drug and its degradation product in different proportions. The data indicated that the method is selective and stability indicating as the presence of degradation product did not interfere up to $60 \%-90 \%$ for both methods.

Table 4. Specificity of the proposed spectrofluorimetric and TLC-densitometric methods for the determination of sertaconazole nitrate in laboratory prepared mixtures with their corresponding degradation products.

\begin{tabular}{|c|c|c|}
\hline \multirow{2}{*}{ Degradation \% } & \multicolumn{2}{|c|}{ \% Recovery ${ }^{\mathrm{a}}$ of intact drug } \\
\cline { 2 - 3 } & Spectrofluorimetric & TLC-densitometric \\
\hline 5 & 98.00 & 99.65 \\
10 & 98.70 & 101.00 \\
20 & 100.05 & 100.90 \\
40 & 100.50 & 102.00 \\
60 & 98.67 & 98.00 \\
80 & - & 101.45 \\
90 & - & 101.69 \\
Mean \pm RSD \% & $99.18 \pm 1.05$ & $101.69 \pm 1.38$ \\
\hline
\end{tabular}

${ }^{a}$ Average of four different experiments.

\section{Applications}

The methods were applied for determination of Ser- $\mathrm{NO}_{3}$ content in two pharmaceuticals. The results showed good agreement with the composition claimed by the supplier as presented in Table 5.

Table 5. Comparison between the proposed methods and the reported methods for the determination of sertaconazole in its pharmaceutical dosage forms.

\begin{tabular}{|l|c|c|c|}
\hline Preparations & $\begin{array}{c}\text { Spectrofluorimetric } \\
\text { method } \\
\text { Mean recovery } \pm \text { RSD \% }\end{array}$ & $\begin{array}{c}\text { TLC-densitometric method } \\
\text { Mean recovery }{ }^{\mathrm{b}} \pm \text { RSD \% }\end{array}$ & $\begin{array}{c}\text { Reported method } \\
\text { Mean recovery }{ }^{\mathrm{a}} \pm \text { RSD \% }\end{array}$ \\
\hline Dermovit 2 \% powder & $98.60 \pm 1.30$ & $101.80 \pm 1.69$ & $99.50 \pm 0.73^{\mathrm{b}}$ \\
Dermovit 2\% cream & $101.20 \pm 1.44$ & $97.86 \pm 2.00$ & $98.00 \pm 1.51^{\mathrm{c}}$ \\
\hline
\end{tabular}

${ }^{a}$ Average of four experiments. ${ }^{b}$ Spectrophotometric procedure (in methanol at $302 \mathrm{~nm}$ ) of the manufacturer supplied by October Pharm (Co., Egypt) in a personal communication. ${ }^{c}$ LC procedure of the manufacturer supplied by October Pharm (Co., Egypt) in a personal communication.

The standard addition method was used in the analysis of these pharmaceuticals. A recovery study was performed by adding three different amounts of Ser- $\mathrm{NO}_{3}$ to each pharmaceutical. The recovery results were found to be between 98.00 and $101.80 \%$, for fluorimetry and 98.50 and $101.60 \%$ for TLC, which are generally quite good, and the relative standard deviation less than $2 \%$ indicating a good precision. The results are given in Table 6. 
Table 6. Results of application of standard addition technique for the determination of sertaconazole nitrate by the proposed methods.

\begin{tabular}{|l|c|c|c|c|c|c|}
\hline \multirow{3}{*}{ Preparations } & \multicolumn{2}{|c|}{ Spectrofluorimetric method } & \multicolumn{3}{c|}{ TLC-densitometric method } \\
\cline { 2 - 6 } & $\begin{array}{c}\text { Amount } \\
\text { taken } \\
\left(\mu \mathrm{g} \mathrm{mL}^{-1}\right)\end{array}$ & $\begin{array}{c}\text { Authentic } \\
\text { added } \\
\left(\mu \mathrm{g} \mathrm{mL}^{-1}\right)\end{array}$ & $\begin{array}{c}\text { Found } \\
\text { recovery } \pm \\
\text { RSD }\end{array}$ & $\begin{array}{c}\text { Amount } \\
\text { taken } \\
(\mu \mathrm{g} / \mathrm{spot})\end{array}$ & $\begin{array}{c}\text { Authentic } \\
\text { added } \\
(\mu \mathrm{g} / \mathrm{spot})\end{array}$ & $\begin{array}{c}\text { Found } \\
\text { recovery }^{\mathrm{a}} \pm \\
\mathrm{RSD}_{\%}\end{array}$ \\
\hline Dermovit 2\% & 1.0 & 2.0 & $100.80 \pm 1.28$ & 4.0 & 1.0 & $99.05 \pm 1.11$ \\
powder & 1.0 & 3.0 & $98.00 \pm 0.85$ & 4.0 & 2.0 & $100.50 \pm 1.31$ \\
& 1.0 & 4.0 & $101.22 \pm 1.60$ & 4.0 & 4.0 & $101.60 \pm 0.70$ \\
\hline Dermovit 2\% & 1.0 & 2.0 & $98.20 \pm 0.59$ & 4.0 & 1.0 & $98.50 \pm 2.00$ \\
cream & 1.0 & 3.0 & $101.80 \pm 0.87$ & 4.0 & 2.0 & $99.05 \pm 1.53$ \\
& 1.0 & 4.0 & $100.60 \pm 1.50$ & 4.0 & 4.0 & $99.61 \pm 1.08$ \\
\hline
\end{tabular}

${ }^{a}$ Average of four different experiments.

\section{CONCLUSIONS}

The developed spectrofluorimetry and TLC methods are sensitive and selective and permit the determination of $\mathrm{Ser}-\mathrm{NO}_{3}$ in pure form, in the presence of its acid, alkaline, oxidative degradation products, as well as in pharmaceutical dosage forms. The methods can be applied for routine quality control testing and drug stability monitoring. In addition, they offer simplicity, fast response and low cost.

\section{REFERENCES}

1. Torres, J.; Marquez, M.; Camps, F. Int. J. Gynecol. Obstet. 2000, 71, 3.

2. Palacin, C.; Tarrago, C.; Ortiz, J. A. Int. J. Gynecol. Obstet. 2000, 71, 36.

3. Brunton, L.; Blumenthal, D.; Buxton, I.; Parker, K. The Goodman and Gilman Manual of Pharmacology and Therapeutics, 10th ed., McGraw-Hill: New York; 2007; p 1239.

4. Sweetman, M.; Martindale, S.C. The Extra Pharmacopoeia, 34 ed., Pharmaceutical Press: London; 2005; p 492.

5. British Pharmacopoeia, Her Majesty's Stationary Office: London, UK; 2008; p 934.

6. Albet, C.; Fernandez, C.; Rozman, J.M.; Perez, J.A.; Sacristan, A.; Ortiz, J.A. J. Pharm. Biomed. Anal. 1992, 10, 205.

7. Emirhan, N.; Ceren, Y.; Nuran, O. Anal. Chim. Acta 2005, 547, 83.

8. Alarfaj, N.; Abdel Razeq, S.; Sultan, M. Chem. Pharm. Bull. 2006, 54, 564.

9. Ocana, J.A.; Barragan, F.J.; Callejon, M.J. Pharm. Biomed. Anal. 2005, 37, 327.

10. Dhavale, N.; Gandhi, S.; Sabnis, S.; Bothara, K. Chromatographia 2008, 67, 487.

11. Antić, D.S.; Filipić, S.; Agbaba, D. Acta Chromatographica 2007, 18, 199.

12. ICH Q2A Note for guidance on validation of analytical methods: definitions and terminology in IFPMA (ed): International Conference on Harmonization; Geneva; 1994.

13. ICH Q2B Note for guidance on validation of analytical procedure: Methodoloy in IFPMA (ed): International Conference on Harmonization; Geneva; 1996. 